\title{
The Design and Implementation of the Work Management System of the Political and Legal Institutions of Higher Political and Legal Institutions
}

\author{
Jieru Xie, Xinde Yang \\ \{xjrrebecca@163.com\}
}

Jiangxi Open University Nanchang 330046, China

\begin{abstract}
Face increasingly complex overelaborate work, relying on the traditional manual counselor management obviously can not meet the development of information technology brings to the social progress and the development of the positive effects, but counselors work supporting management software for serious lack of development a counselling for employee information management system, strengthening class management, improve office efficiency and quality, to meet the requirements of all aspects of the school development in the new era, is present in the student management work in urgent to solve the problem. In order to strengthen and facilitate the management of students in Institutes of political science and law, reduce human errors in counselor workload and work, the relevant departments special to determine the "politics and law college counselors work management information system" to study the subject. Structure is used in the system is a B / S structure, using ASP. Net development environment and SQL Server 2005 database to design and development, and use oriented object and unified modeling language of the system for analysis and design. This topic is simple, briefly describes the background and environment of development of counselor work management information system, the architecture of the system of detailed analysis and thus is divided into various modules: teacher module, student module, the administrator module. Under the three modules, and subdivided to modify information, student information, performance management, scholarship management, reviews management, work plans, and other small modules. On the basis of the analysis, the paper makes a detailed introduction about the realization principle of each module and function of the system.
\end{abstract}

Keywords: Instructor; student management; object oriented; unified modeling language.

\section{Introduction}

With the rapid development of education in China, the number and size of the higher education institutions continue to expand, at the same time, the political and legal education has been the strong support of the national policy. With the development trend, the number of students 
of political science and law college is increasing day by day. Therefore, the student's management work to a great extent will affect the overall development process. Affected by this, the Institute of political science and law has carried on the internal reform, expanded the enrollment scale, has improved the student management system, has introduced the full-time instructor troop. At present, the concept of higher education in our country is changing from the traditional to the modern type, and the thinking mode of university administrators has been changed gradually. And higher education management in supporting the work of counselors should become the main body of the work, and not just stay in the previous "nurse" role, but should liberated, become an ideological education workers, and in college life[1], learning and guidance, to establish the correct values, and gradually adapt to the development needs of the times. Under such background, the Institute of political science and law has carried on the internal reform, expanded the enrollment scale, has improved the student management system, has introduced the full-time instructor troop. Face increasingly complex overelaborate work, relying on the traditional manual counselor management obviously can not meet the development of information technology brings to the social progress and the development of the positive effects, but counselors work supporting management software for serious lack of development a counselling for staff management system, improve the quality of office, strengthening class management, adapt to the school the development requirement and the student management work is needed to resolve problems. In order to facilitate the management of students in political and legal institutions, reducing the workload of counselors and human errors in the work, the college has identified the "political and legal institutions of the work of counselors work management information system". At the same time, existing counselors have computer application office of basic quality, Institute of network and information technology have achieved obvious progress, such a management information system, conditions in the school of existing computer network and based on the build and will not increase too much extra expenses, therefore, on the basis of the improvement of the existing software and hardware conditions and management needs, counselors work management information system construction is necessary.

\section{System Related Technology Analysis}

WEB technology based on B/S mode, the application platform and application platform and programming language independent way to communicate with each other a information technology. Internet information expression is mainly ultra media (hypermedia) and hypertext (hypermedia) and two classes, the basic principle is using hypermedia and hypertext will link information to cover the whole Internet, but such a way can is a fixed, linear type. And web to realize fundamentally solve this problem, although it is also a kind of hypertext information system, but based on Web text can from a position to jump to a different location, users can more convenient, quick access to more information, just click on the wants to know about the content of keywords, you can jump to the keywords contained in the text, the connectivity constitutes the web [2]. 


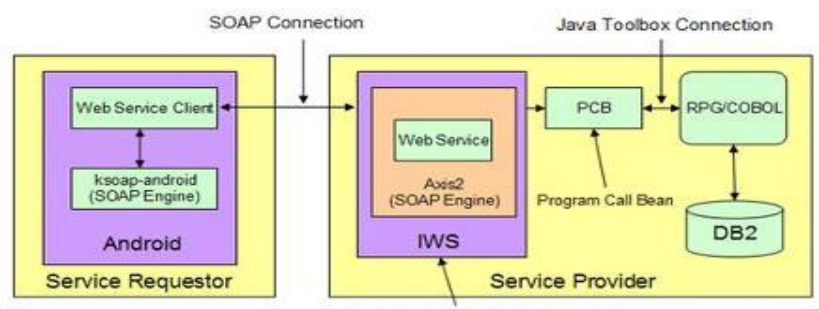

Fig. 1. Web system structure diagram

\subsection{Overview of B/S Architecture}

B/S structure mode (Browser / server mode) prevailed in the end of 1990s and is still used by most people. $\mathrm{B} / \mathrm{S}$ architecture system has the basic characteristics and advantages of the traditional three layer $\mathrm{C} / \mathrm{S}$ system. At the same time, the structure mode of $\mathrm{B} / \mathrm{S}$ is a unique form of the three layer C/S system. In the three layer mode, the first layer is the presentation layer, which is used in the browser business information; the second layer is the business logic layer running on the application layer; the third layer is the data layer to complete the data management and storage. The development of the system using B / S mode, mainly due to the B / s Application of the Internet, convenient maintenance, etc. the utility model, B / S mode by the client browser send HTML requests and reach the web server, after processing and scheduling of ASP. Net, in order to achieve data access and operation, and through the browser will corresponding data in html is displayed to the user, realizes the interaction of B / S mode. In combination with the actual situation of the management information system of the counselors, the development model of this system adopts the B/S development model [3].

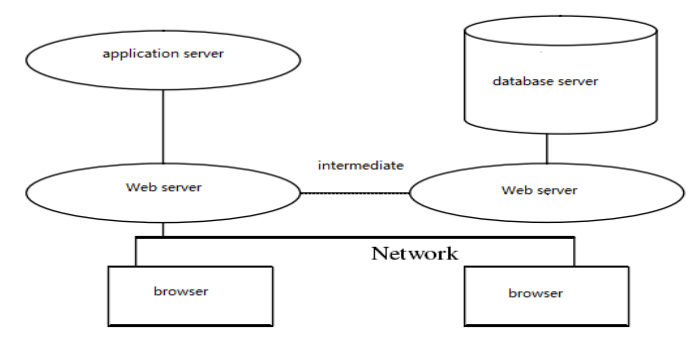

Fig. 2. Schematic diagram of $B / S$ architecture

\subsection{Object Oriented Technology Analysis}

The object oriented system is composed of a set of interacting objects, which maintain the local state and provide the operation to the state. From the middle of 1980s, the object oriented programming language and the design method of program design gradually entered the stage of 
history, a large number of new, object-oriented programming language emerged, object-oriented software development technology is nearly 30 years of software system construction is one of the most popular technologies in the field of object oriented design method is a kind of method of things will abstract, virtual objects through the program to simulate the way out for processing, it emphasizes that in the process of software development for the objective world or problem domain objects, using the cognitive method of human thinking of the objective world intuitive description of the objects in the real world. Object oriented design (Design Object-Oriented, OOD) is one of the methods of software design. OOD aims to "solve the relationship between the object and the class, that is, roles, responsibilities, cooperation, etc.". Object oriented design method is not associated with a specific programming language, but in the form of objects to describe things, and the final realization of the system is still need to use object-oriented programming language to express. Mastery oriented object design pattern on the premise is to first grasp the "object oriented", mainly has the following several stages: understanding and definition of context and system usage patterns; design system; identify the main object in the system; model design; descriptions object interface and the like. Sichuan Vocational and Technical College counselors work management information system design and development, is based on the $\mathrm{C \#}$ language, but also can be used to support the.NET framework of all the.NET language design and development [4].

\subsection{Object oriented Programming}

Object oriented programming (programming Object-oriented, OOP) is an effective way to program design through the object oriented approach. Through the research on the development process of various language shows, oriented object program design allows objects to be separated, in a great extent solves the crisis in the program design in the field of large and medium-sized programs in most of the functions can not be reused. The core of object-oriented program design is the object, each object has its own unique properties and behavior, it can not only receive data, but also can process the data and transfer it to other objects. Oriented object programming against the background of the software system and the reality of social relations, and enhance the program design of sensory understanding, simplify the abstract business logic, enhanced the programming flexibility, efficiency and maintainability. Object oriented programming is easy to learn and easy to learn, so it is widely used.

\section{$3 \quad$ System Design and Implementation}

System configuration schematic diagram is used to reflect the system's hardware and software in the system is how to configure the, in Sichuan Vocational and technical college counselors work management information system, the web application will save in Sichuan Vocational and technical college counselors work management information system application server, and manage related data from the database. In addition system, the client will by a lot of terminal together, to achieve and optimize the system each function index and business logic object bag containing the is mainly to use the ASP. Net framework based interaction with the user interface, they belong to 
one business layer code. The business logic object package generates a user interface, which is the core of the whole system. At the same time, the business logic object package can also carry out the interaction of the database by calling the tool component package, and generate the specific control. Each interface in the data package has a corresponding SQLHelper, which is mainly used to help the implementation of SQLHelper class, and it is also the main interface. Data package mainly uses the Server SQL 2005 framework to access the database through SQLHelper.

Because the counselor is by the administrator can from the background added and in addition to the teacher management module counselors have permission to operate outside the teachers and administrators of other permissions is the same, so in front of their page is the same, including student management, appraisal management, performance management, scholarship management, comment management, work plan, and modify the data module, counselor module function design are the key points of design of the whole system, but also the whole system can be realized a difficult. The database is used to store the system data, the most common function in the management system is the connection and query of the database. The first condition of database access in Asp.Net is to open up the connection with the database, and then pass the command, execute the order and return the result. By writing SQL helper class solid commonly used database implementation related function to simplify the operation of the database, the norms and the system code is simple, and thus more conducive to the establishment and perfection of the management system [5].

\section{Conclusion}

At present, the daily management of the students in Colleges and universities distinctive, have to say goodbye to the traditional manual mode of operation, but actively use advanced, innovative technology, to achieve student daily management system and information. So that is mainly engaged in student management work instructor teacher from the harassment to which the complex manual operation truly liberated, more energy and effort to actively into the education and management of students, concerned about the state of mind of students, care for students of physical and mental health, concern for student's life behavior. In view of this situation, this paper starts from the daily work of college counselors management, combined with the specific information of the digital, the design of the management information system.

\section{References}

[1] Luo Shaoye, the Yellow Sea. The analysis and design of the university class management system based on. ASP.NET Journal of Langfang Teacher's College (NATURAL SCIENCE EDITION). No. 03. (2014)

[2]. Qi Manman. Thinking. Heihe education college class management. No. 06. (2013)

[3] Xiao Xin. Design and implementation of student information management system based on JSP technology. Silicon Valley. No. 07. (2011)

[4] Tang Lin, Ren Liang. Analysis and design of the attendance management system of Higher Vocational College Students. science and technology information. No. 08. (2010)

[5] Peng Lijun. The strategy of the management of college counselors under the information environment [J]. 
Journal of Jilin College of Education (subject Edition). No. 03. (2012) 